\title{
The Modeling and Design on Automatic Control System for Hydraulic Log-core Veneer Lathe
}

\author{
Xiong Guangming ${ }^{1, a}$, Guo Lijun ${ }^{1, b^{*}}$ \\ ${ }^{1}$ College of Aeronautics and Astronautics, University Xiamen, Xiamen, 361005, China \\ ${ }^{a}$ xgm@xmu.edu.cn, ${ }^{\text {b* }}$ glj@xmu.edu.cn
}

\begin{abstract}
Keywords: log-core veneer lathe; control system; single chip computer; displacement sensor, flow control

Abstract. The mathematical variable speed feeding model of the cutter is established in this paper, the curve of the cutter's feeding speed with the diameter of the log changed is deduced and a new-style hydraulic log-core veneer lathe control system is designed by the model. C8051F020 type single-chip becomes controlling core. The displacement sensor is used to measure and feedback the diameter of the log, control the solenoid-operated proportional flow valve, automatically regulate the feed flow of the hydraulic system then control the feeding speed of cutters. The result shows that the precision and uniformity of veneer thickness are advanced by the electro-hydraulic proportional control technology. The peeling precision is $\pm 0.02 \mathrm{~mm}$. The error of veneer thickness accords with the design.
\end{abstract}

\section{Introduction}

During the manufacturing and machining process of wood, the veneer lathe can peel the log into veneers or splints which can be used to be the production of plywood or decorative overlays of wood-based panels. But the main problem is the precision and the uniformity of the veneer thickness. For precision veneer lathe, the precision of the veneer thickness can be $\pm 0.02 \mathrm{~mm}$ abroad [1]. Now, mechanical log-core veneer lathes occupy a dominant position of markets, and most of them are driven by adjustable-speed motor. The feed of cutters is carried out by guide screw. The guide screw can be easily worn out. It has loud sound level, short life-span and large vibration, etc. It must be replacing about half a year. The precision and uniformity of veneer thickness are difficult to be ensured [2]. A new-style hydraulic log-core veneer lathe which is controlled by electro-hydraulic proportional valve is designed. The guide screw is taken out and the hydraulic driving is substituted for adjustable-speed motor system. The hydraulic log-core veneer lathe has less friction, lower sound level, lower power wastage and steady working etc. The life-span of the hydraulic cylinder is more than ten years. The precision and the uniformity of the veneer thickness are ensured. There are better economic profitability and wide extension value.

\section{The Mathematical Model of Veneer Lathe}

The system sketch of the veneer lathe is shown in Fig. 1. Driving roller 1、2 and press roll 3 contra rotate. The cutter fixed on the press roll 3 is fed at the speed $\mathrm{v}$. When the rotating speed $n_{0}$ of the driving roller 1、2 and the press roll 3 keep on constant, the rotating speed of the $\log$ is $n$ and the rotating speed $n$ of the log will be changed. Supposing that there is no relative sliding among the driving rollers, press roll and the log, then the tangent linear velocity of the log is constant. So, in rotary cutting process, the feeding speed $\mathrm{v}$ of the cutter must be changed continuously according to the law, the hydraulic log-core veneer lathe can peel veneer with the same thickness $\mathrm{m}$ and work well.

Here,

$\mathrm{d}$ : the diameter of driving roller $1 、 2$ and press roll $3(\mathrm{~mm}) ; n_{0}$ : rotating speed of the driving roller 1、 2 and the press roll $3(\mathrm{r} / \mathrm{min})$; $\mathrm{D}$ : the diameter of the $\log (\mathrm{mm}) ; \mathrm{m}$ : peeling thickness $(\mathrm{mm})$; a: the central distance between the driving roller 1 and the driving roller $2(\mathrm{~mm})$; v: feeding speed $(\mathrm{mm} / \mathrm{min}) ; \mathrm{n}$ : the rotating speed of the $\log (\mathrm{r} / \mathrm{min})$; 


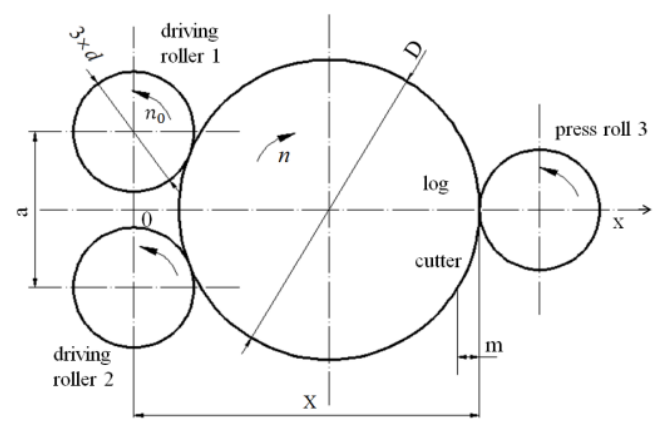

Fig. 1 The system sketch of the veneer lathe

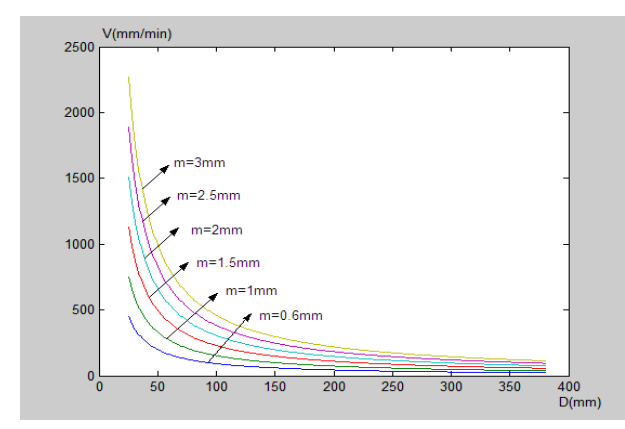

Fig. 2 The changing curve between the feeding speed $v$ and the diameter $\mathrm{D}$ of the $\log$

Supposing that there is no relative sliding among the driving rollers, press roll and the log, and driving roller 1, 2 are fixed. In the rotary cutting process, on the one hand the log rotates around its axis, on the other hand, it also does the central horizontal moving to the driving roller 1 and 2 , under the action of press roll 3, The tangent linear velocity of the log is equal to that of the driving rollers, it is shown in Eq. 1.

$$
D \times n=d \times n_{0}
$$

In the rotary cutting process, when the rotating speed $n_{0}$ of the driving rollers keep on constant, the rotating speed $n$ of the $\log$ is increasing with the diameter of the log decreasing. The edge of the cutter is in the symmetrical center plane between the driving rollerland 2, the horizontal coordinates of the edge of the cutter, refer with Eq. 2.

$$
x=\frac{D}{2}+\frac{1}{2} \sqrt{(D+d)^{2}-a^{2}}
$$

Calculate the first derivative of equations (2) about the time t. Thus the horizontal moving speed of the tangent point will be got, see the Eq. 3 .

$$
v=\frac{d x}{d t}=\frac{1}{2} \times\left[1+\frac{D+d}{\sqrt{(d+D)^{2}-a^{2}}}\right] \times \frac{d D}{d t}
$$

Substitute equations (1), and $\frac{d D}{d t}=-2 \times m \times n$ into equations (3),

Thus there will be got Eq. 4 .

$$
v=\frac{d x}{d t}=-\left[1+\frac{D+d}{\sqrt{(D+d)^{2}-a^{2}}}\right] \times m \times \frac{d \times n_{0}}{D}
$$

The negative sign of equations (4) implies that the direction of $\mathrm{V}$ is in the opposite direction of the coordinate axis.

In order to guarantee the same thickness of the veneer, the feeding speed $\mathrm{v}$ of the cutter should content equations (4). Choose:

$$
a=97 \mathrm{~mm}, m=0.6-3 \mathrm{~mm}, n_{0}=74 \mathrm{r} / \mathrm{min}, D_{\max }=380 \mathrm{~mm}, D_{\min }=25 \mathrm{~mm}, d=96 \mathrm{~mm}
$$

Substitute above parameters into equations (4), simulate with matlab software, thus we can get the changing curve of the feeding speed $\mathrm{v}$ with the diameter $\mathrm{D}$ of the log changed. It is shown in Fig. 2.

From Fig. 2 we can see that when the diameter $d$ 、 the central distance a 、 rotating speed 、 peeling thickness $\mathrm{m}$ are constant, in the rotary cutting process, the diameter $\mathrm{D}$ becomes smaller and smaller, while the feeding speed $\mathrm{V}$ of the cutter becomes bigger and bigger. The bigger the thickness $\mathrm{m}$, the faster the feeding speed $\mathrm{V}$ of the cutter. 


\section{Flow Analysis of Hydraulic System}

The speed of the hydraulic cylinder is equal to that of the round log; the flow of hydraulic cylinder is shown in Eq.5.

$$
q=2 S V=2 \times \frac{\pi d_{0}}{4} V=\frac{\pi d_{0} V}{2}
$$

Here:

$v$ : the horizontal feeding speed $(\mathrm{m} / \mathrm{s})$ of the round $\log$, i.e., the speed of hydraulic cylinder;

$d_{0}:$ the diameter of the hydraulic cylinder $(m)$;

$s$ : rodless cylinder piston's area $\left(m^{2}\right)$.

In hydraulic control system, in order to make hydraulic cylinder be adaptable for use in different sizes, hardness and the peeling speed changing of the round log, the electromagnetic proportional flow valve is used to control the flow, which makes the flow into the hydraulic cylinder be proportional to the input current. Experiment has proven that electromagnetic proportional flow valve has a good advantage of following trace of the moving control system. The output flow of electromagnetic proportional flow valve can be written as Eq.6.

$$
q=k_{1} k_{2} i
$$

Here:

$k_{1}$ : voltage proportional coefficient.

$k_{2}:$ the amplified gains of electromagnetic proportional flow valve.

$i$ : current $(A)$.

Hydraulic system flow control is the key to the developing of this control system. The kinematics and dynamic analysis between the veneer lathe and the round log shows that the uniform thickness of the board needs the hydraulic cylinder to operate in accordance with the given laws, the flow control of hydraulic cylinder depends on equation (6). The functions of the control system are controlling the flow of the electromagnetic proportional flow valves. The control system is designing as following.

\section{The Design and Principle of the Control System}

To improve the controlling accuracy of the feeding speed and consider different kinds of cases such as: cost and convenience operation and so on, the single chip computer C8051F020 is chosen as the core of the control system, displacement sensor is used to measure the position of the knife and feedback the diameter of the round log, the control system apply digital display and the keyboard input operation. Its structure diagram is shown in Fig.3.

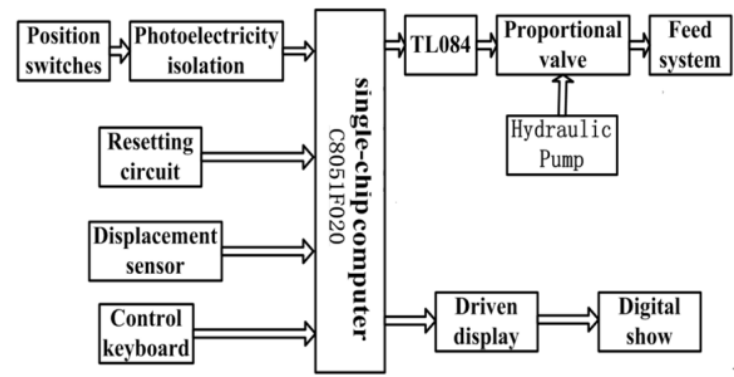

Fig.3 The control system diagram of the log-core veneer lathe

To obtain the moving size of the round log, the system uses displacement sensor DXC-A. Displacement sensor DXC-A adopts sliding bar with totally-sealed devices, it can provide positional information within the moving region, and it can output direct current signal. The main technical parameters of displacement sensor DXC-A, the output currents: 4-20(mA), position precision: 1\%, resolution ratio: $0.1 \%$. 
The displacement signal of the feed system outputs current 4-20(mA) through the displacement sensor. The resistance is in the cycle circuit of the displacement sensor, it can convert current signals into voltage signals. Single chip computer judges the direction of movement according to the high or low voltage signals. If the voltage signals are from low to high, it indicates that the system forwards. if the voltage signals are from high to low, it indicates that the system returns. Single chip computer keeps records of the moving displacement at any time.

The changing law of variable speed feed movement of the cutter is confirmed by the mathematical model. The flow of the solenoid-operated proportional valve is automatically controlled by the singlechip in order that the cutter peels the log at the given rotary speed. In rotary cutting process, with the diameter of the log decreasing, the output feedback current signal is measured by the displacement sensor. The current signal is converted to a voltage signal which is fed back to the singlechip and achieved A/D conversion in the singlechip. The digital signal is compared with the given computational amount, which supplies error signals according to the error requirement of the veneer precision to adjust the output flow of the proportional valve, control the flow of the hydraulic cylinder then adjust the feeding speed of the cutter to content the requirement of the precision and the uniformity of thickness.

To optimize software design of the system, the software architecture chooses modular structure and the explanation of top-down methods, including keyboard scanning procedures, data selection module, decoding driven show module, ADC conversion modules, DAC conversion modules.

After the first electric initialization, the systems set the initial signs of various working conditions, the thickness of the veneer processing tabulation, a timer control characters working methods, and then click the keyboard to the next work.

\section{Conclusions}

In practical use, the maximum rotary cutting diameter of the $\log$ is $\Phi 400(\mathrm{~mm})$, the residual diameter of the $\log$ core is less than $\Phi 30(\mathrm{~mm})$, the veneer thickness is $0.6 \sim 3.0(\mathrm{~mm})$, and the precision of the veneer thickness is $\pm 0.02 \mathrm{~mm}$ which contents the error requirement of the veneer thickness. Comparing with the traditional mechanical system, the improved system which is substituted hydraulic driving for traditional guide screw driving has smooth transferring movement, better lubricity, lower sound level, lower energy wastage, less friction and longevity etc. The working condition of workers is improved. The automation is greatly developed. Certainly, the hydraulic system is easy to leak and the change of oil temperature can influence the hydraulic transmission performance, these questions will be researched further.

\section{References}

[1] Fu wan si, The present situation and developing predication for Chinese woodworking machinery, Wood Processing Machinery, 2002, 5, pp. 2-6.

[2] Wei wei, Xi ping yuan, The research and design for timber lathe and its mechanism feed, Machine Design and Research, 2004, 20(3), pp. 19-20.

[3] Guo chuan xiang, Zhang zhi xue, Designing a Computer Control System for Spindleles Lathes, China Wood Industry, Vol.19 No.6, pp. 37 41.

[4] PAN Zhuojin, The manual of ISP FLASH micro-controller with C8051F020/1/2/3 mixed signal, Shenzhen, New Hualong Electron Limited Company, 2005.

[5] GB/T 2348-1993, The manual of mechanical and designed, Edition (3), Vol.(4).

[6] Hydraulic transmission in the manual of mechanical engineering (the thirty-four book). 